\title{
Integrated management of new-found pests on bottle gourd rootstocks and watermelon graft-unions in greenhouse
}

\author{
Sun Yuhong ${ }^{\circledR 1, a}$, Zhang $\mathrm{Na}^{\circledR 1, b}$, Shi Xianfeng ${ }^{1, \mathrm{c}}$, Tang $\mathrm{Mi}^{1, \mathrm{~d}}$, Zhou Mobing ${ }^{1, \mathrm{e}}$, \\ Cheng Weishun ${ }^{1, f}$, Zeng Hongxia ${ }^{1, g}$, Li Yuhua ${ }^{1, h}$, Ren Jian $^{1, i}$ and Peng \\ Jinguang ${ }^{2, *}$ \\ ${ }^{1}$ Wuhan Institute of Agricultural Sciences, Wuhan, Hubei, China \\ ${ }^{2}$ Dongxihu District Institute of Agricultural Sciences, Wuhan, Hubei, China \\ (O) These authors contributed equally to this work \\ asunyh68@163.com, bzn800329@163.com, '821648773@qq.com, dtommy512@163.com,

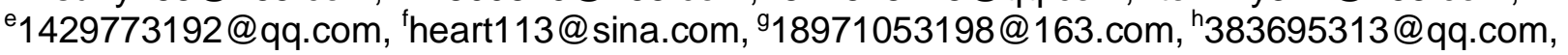 \\ i408449295@qq.com, *393089592@qq.com
}

Keywords: bottle gourd rootstocks, watermelon graft-union, Lycoriella pleuroti, Scatella tenuicosta, pest management

Abstract. Lycoriella pleuroti Yang et Zhang (Diptera : Sciaridae) and Scatella tenuicosta Bennison (Diptera : Ephydridae) have become major pests on greenhouse seedlings and caused lots of economic losses, which has greatly restricted the development of modern facility agriculture in Wuhan. We reported here the first integrated management of new-found pests on bottle gourd rootstocks and watermelon graft-unions in greenhouse. In this study, we conducted pretreatment to control pest population in greenhouse by isothiocyanate and dichlorvos (DV). The treatment reduced 72.8-77.3\% adult pests compared with control. Moreover, we conducted two kinds of methods to protect bottle gourd rootstocks and graft-unions from pest damage, i.e. pesticide-mixed soil for sowing and DE covering. The results showed low or no toxicity to bottle gourd seedlings and the protection efficiency arranged from $75-100 \%$. This study will be a guideline for facility cultivation of watermelon. The application of safe and low toxic pesticides will greatly improve the quality and safety of watermelon products, which is also beneficial for the sustainable development of facility agriculture.

\section{Abbreviations}

YST, yellow sticky trap; DV, dichlorvos; DE, diatomaceous earth; ITC, isothiocyanates; AA, avermectin azadirachtin EC; PG, phoxim granule.

\section{Introduction}

Lycoriella pleuroti Yang et Zhang (Diptera : Sciaridae) is a pest of edible fungi [1] and . Scatella tenuicosta Bennison (Diptera : Ephydridae) is a common greenhouse pest [2]. Recently years, these two kinds of pests have become major pests on greenhouse seedlings and caused lots of economic losses, which has greatly restricted the development of modern facility agriculture in Wuhan [3]. There have been some reports about the biological characteristics and habits of the two pests [4,5] and a series of pest control has also been reported in many plants [6-9]. However, no related study has been reported to protect watermelon or bottle gourd seedlings in greenhouse. Watermelon (Citrullus lanatus) is an important cucurbit fruit with high production about 90 million tons in the world (http://faostat.fao.org/). Till now, facility cultivation has been widely used in watermelon production, which is high efficiency in land utilization and cultivation management. Moreover, grafting technology is also widely applied to improve watermelon quality and bottle gourd is commonly selected as rootstocks [10]. Therefore, watermelon graft-unions and bottle gourd rootstocks are usually vulnerable to greenhouse pests and an effective method for pest management is urgently needed in watermelon production. 
Chemical pesticides were once commonly used to kill pests for their high toxicity, such as phoxim [11]. With the enhancement of environmental consciousness, environment-friendly pesticides have been replacements of chemical pesticides, such as azadirachtin and isothiocyanate (ITC) [12]. Azadirachtin was isolated from neem with multifunction [13], especially for pest management $[\underline{3}, 14]$. ITC was also plant-based material and had excellent performance for pest management [15-18]. Besides, diatomaceous earth (DE) has also been used in pest control without toxicity, chemical residue and pollution $[\underline{19}, \underline{20}]$. We reported here the first integrated management of new-found pests on bottle gourd rootstocks and watermelon graft-unions in greenhouse. In this study, we first compared the efficiency of isothiocyanate and dichlorvos (DV) to control pest population in greenhouse. Moreover, we conducted two kinds of methods to protect bottle gourd rootstocks and graft-unions from pest damage, i.e. pesticide-mixed soil for sowing and DE covering. The results will be a guideline for facility cultivation of watermelon. The application of safe and low toxic pesticides will greatly improve the quality and safety of watermelon products, which is also beneficial for the sustainable development of facility agriculture.

\section{Materials and Methods}

Plant material and grafting. This study was conducted in production base of Weinong company (Dongxihu district of Wuhan city) from April 2011 to May 2012. Bottle gourd 'Jingzhen No.1' was selected as rootstock and watermelon 'Exigua No. 1' was used as grafted plants. When each seedling had developed cotyledons, watermelon shoots were grafted onto bottle gourds according to a previous method [10]. All plants were planted on seedbed frames $\left(44 \times 0.9 \mathrm{~m}^{2}\right)$ in automatic temperature and humidity controlled glass greenhouses $\left(5000 \mathrm{~m}^{2}\right)$.

Pretreatment in greenhouse before sowing. Before sowing, the ground was managed to reduce pest population in greenhouses. Firstly, the ground was strewed with quicklime $\left(0.5 \mathrm{Kg} / \mathrm{m}^{2}\right)$ and covered with black plastic film. Secondly, diluted 2000 (P1), 3000 (P2) times 98\% ITC (60 mushes, produced by ourselves using vegetable matter) and 2000 times (P3) 80\% DV (Sanonda Co.Ltd., Wuhan) were sprayed in three different greenhouses, respectively. A greenhouse without management was set as control. 247 YSTs $\left(20 \times 25 \mathrm{~cm}^{2}\right.$, Pherobio Technology Co.Ltd., Beijing) were placed in each greenhouse and the insecticidal efficiency of pretreatment was evaluated by the number of adult pests on YSTs after 75 days.

Pesticide-mixed soil for sowing and DE covering. We tested two kinds of methods for pest management on bottle gourd, i.e. mixing soil for seed tray (72 holes) with different pesticides or covering pesticide-mixed DE on the surface of seed tray with normal soil. The soil for seed tray was mixed with different contents of different pesticides. DE (Xinshi Mining Co.Ltd.) was mixed with soil at five weight ratios (1:10, 1:20, 1:40, 1:80 and 1:160). ITC, AA (0.8\%, Lvjin Biotech, Chengdu) and PG (3\%, Dahe Agrichemical, Zhengzhou) were also mixed with soil at five weight ratios (1:20, 1:40, 1:80, 1:160 and 1:320). Soil without pesticides was set as control. For covering, ITC, AA and PG were mixed with DE at five weight ratios (1:20, 1:40, 1:80, 1:160 and 1:320). Pesticide-mixed or pesticide-free DE were covered on the surface of seed trays (70 $\mathrm{g}$ for each tray). Soil covering was selected as control. In the two tests, eight seed strays were divided into four replicates and all these tests were conducted for twice, respectively at December, 2011 and February, 2012.

Phytotoxicity of different pesticides was evaluated at ten days after germination of bottle gourd. Pest biting was evaluated on graft-unions at one month after grafted.

\section{Results}

The effect of pretreatment on pest population before sowing. We calculated the average number of adult pests on each YST at 75 day after pretreatment. The result was shown in Figure 1. We found there were less than 400 pests on each YST in pretreatment P1, P2 and P3, which was less than $25 \%$ of the control. 
Figure 1: Average number of adult pests on each YST.

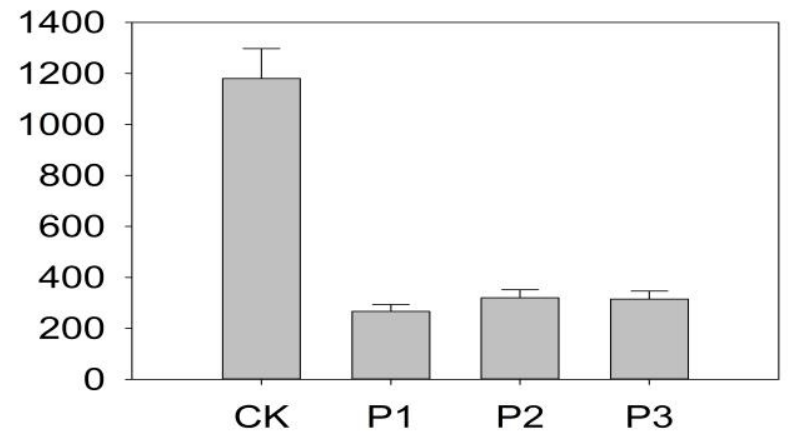

The capitals on the $\mathrm{x}$-axis represent the control (CK), diluted $2000(\mathrm{P} 1), 3000(\mathrm{P} 2)$ times 98\% ITC and 2000 times (P3) 80\% DV. The y-axis represents pest number. The error bar represents the standard error.

The effect of pesticide-mixed soil on germination and pest management. We examined the effect of pesticide-mixed soil on bottle gourd germination (Figure 2). The results showed that DE has little effect on germination. High content of ITC (1:20) had significantly reduced the number of germinated bottle gourd more than 50\%. Moreover, High contents of AA and PG (1:20, 1:40) had slightly impacted germination bottle gourd.

Figure 2: Average number of healthy bottle gourd seedlings on each two seed trays with pesticide-mixed soil.

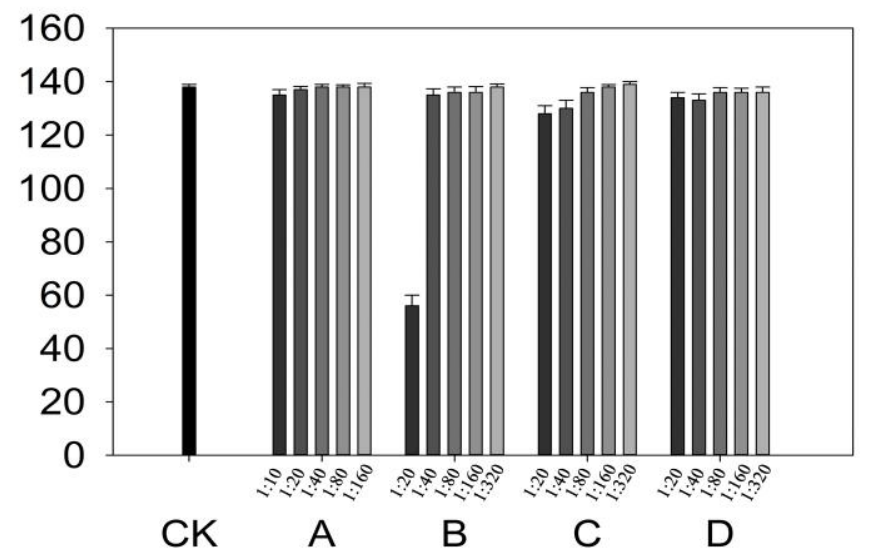

The capitals on the $\mathrm{x}$-axis represent the control (CK), DE (A), ITC (B), AA (C) and $P G$ (D). The numbers on the $x$-axis represent weight ratios. The $y$-axis represents seedling number. The error bar represents the standard error.

After grafted, we examined the effect of pesticide-mixed soil on pest management of graft-unions. According to Table 1, 43.03\% graft-unions were damaged by pest in control while there were less than $11 \%$ damaged graft-unions in different treatments. DE and ITC had slightly better effect on pest management than AA and PG.

Table 1: Damaged number, damaged rate and control effect of watermelon graft-unions on each two seed trays with pesticide-mixed soil.

\begin{tabular}{ccccc}
\hline Pesticides & Weight Ratio & $\begin{array}{c}\text { Damaged } \\
\text { Seedlings }\end{array}$ & $\begin{array}{c}\text { Damaged Rate } \\
(\%)\end{array}$ & $\begin{array}{c}\text { Control Effect } \\
(\%)\end{array}$ \\
\hline CK & - & 241 & 43.03 & - \\
\hline \multirow{2}{*}{ A } & $1: 10$ & 26 & 4.6 & $89.3 \mathrm{a}$ \\
& $1: 20$ & 28 & 5 & $88.5 \mathrm{a}$ \\
& $1: 40$ & 33 & 5.9 & $86.2 \mathrm{a}$ \\
\hline \multirow{3}{*}{$\mathrm{B}$} & $1: 80$ & 29 & 5.2 & $87.9 \mathrm{a}$ \\
& $1: 160$ & 33 & 5.9 & $86.2 \mathrm{a}$ \\
& $1: 320$ & 35 & 6.2 & $85.6 \mathrm{a}$ \\
\hline & $1: 80$ & 57 & 10.1 & $76.5 \mathrm{a}$ \\
& $1: 160$ & 61 & 10.9 & $75.7 \mathrm{a}$ \\
& $1: 320$ & 60 & 10.7 & $79.3 \mathrm{a}$ \\
\hline & $1: 80$ & 50 & 8.9 & $78.6 \mathrm{a}$ \\
& $1: 160$ & 52 & 9.2 & $78.1 \mathrm{a}$ \\
\hline
\end{tabular}


The effect of DE covering on germination and pest management. The effect of covering was also examined on bottle gourd germination. We found that all treatments had slight influences on bottle gourd germination (Figure 3).

Figure 3: Average number of healthy bottle gourd seedlings on each two seed trays covering by DE.

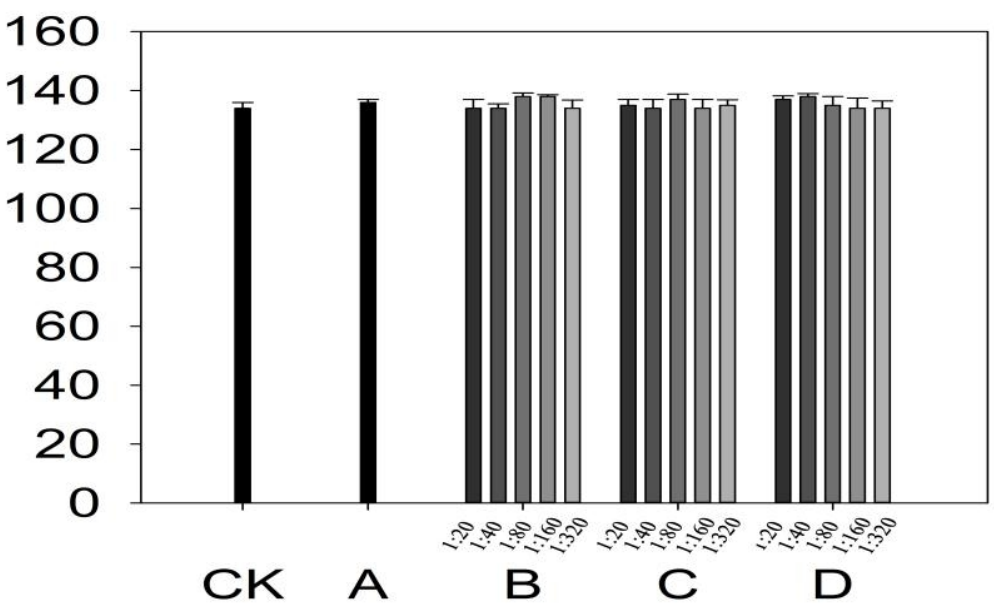

The capitals on the $\mathrm{x}$-axis represent the control (CK), DE (A), ITC (B), AA (C) and PG (D). The numbers on the $\mathrm{X}$-axis represent weight ratios. The $y$-axis represents seedling number. The error bar represents the standard error.

After grafted, pest damaged graft-unions were counted to evaluated their effects on pest management. Few graft-unions were damaged by pests in each treatment (Table 2). Nearly all graft-unions were protected by DE covering compared to $56.97 \%$ in control.

Table 2: Damaged number, damaged rate and control effect of watermelon graft-unions on each two seed trays covering by DE.

\begin{tabular}{ccccc}
\hline $\begin{array}{c}\text { Pestici } \\
\text { des }\end{array}$ & Weight Ratio & $\begin{array}{c}\text { Damaged } \\
\text { Seedlings }\end{array}$ & Damaged Rate (\%) & Control Effect (\%) \\
\hline CK & - & 241 & 43.03 & - \\
\hline A & - & 1 & 0.17 & $99.60 \mathrm{a}$ \\
\hline \multirow{3}{*}{ B } & $1: 80$ & 0 & 0 & $100.0 \mathrm{a}$ \\
& $1: 160$ & 0 & 0 & $100.0 \mathrm{a}$ \\
\hline & $1: 320$ & 1 & 0.17 & $99.60 \mathrm{a}$ \\
\hline & $1: 80$ & 0 & 0 & $100.0 \mathrm{a}$ \\
& $1: 160$ & 0 & 0 & $100.0 \mathrm{a}$ \\
$\mathrm{D}$ & $1: 320$ & 2 & 0.35 & $99.19 \mathrm{a}$ \\
& $1: 80$ & 0 & 0 & $100.0 \mathrm{a}$ \\
& $1: 160$ & 0 & 0 & $90.0 \mathrm{a}$ \\
\hline
\end{tabular}

\section{Discussion}

In this study, we conducted a series of tests to control new-found pests in greenhouse. Pretreatment on ground with ITC or DV could effectively decrease pest population (Figure 1). We further conducted two kinds of methods to protect bottle gourd rootstocks and graft-unions from pest damage, i.e. pesticide-mixed soil for sowing and DE covering. By contrast, covering had a more effective protection than pesticide-mixed soil. Moreover, covering cost less pesticides and the operation was more convenient in facility agriculture.

We further compared the effects of different pesticides on pest control. In pretreatment, we found the plant-based material, ITC, was as effective as chemical pesticide on controlling pest population. Moreover, the compound biological pesticide, AA, was also as effective as chemical pesticide for protecting Cucurbit plants. ITC has already been used for pest control in other plants [15], which is less harmful than chemical pesticides [12]. Interestingly, we found that DE also had an effective 
protection for Cucurbit plants. DE has also been used in pest control without toxicity, chemical residue and pollution $[19,20]$. The application of these 'green' pesticides will greatly improve the quality and safety of watermelon products, which is also beneficial for the sustainable development of facility agriculture.

\section{Conclusion}

Integrated pest management is the key to controlling the damage of plants. In this study, we conducted an integrated management of new-found pests on bottle gourd rootstocks and watermelon graft-unions. We found that pretreatment with ITC or DV could effectively reduce pest population in greenhouse. Moreover, DE, ITC, AA or PG could effectively protect bottle gourd rootstocks and watermelon graft-unions from pest biting without phytotoxicity. The application of safe and low toxic pesticides will greatly improve the quality and safety of watermelon products, which is also beneficial for the sustainable development of facility agriculture.

\section{Acknowledgement}

This research was supported by a grant from the sub-project of the Public Welfare Sector (Agriculture) Project Special Scientific Research Funds (201303014-06).

\section{References}

[1] Shen D-R, Zhang H-R, Li Z-Y, He S-Y, Zhang T (2009) Taxonomy and dominance analysis of sciarid fly species (Diptera: Sciaridae) on edible fungi in Yunnan. Acta Entomologica Sinica 52: 934-940.

[2] Castrillo LA, Ugine TA, Filotas MJ, Sanderson JP, Vandenberg JD, et al. (2008) Molecular characterization and comparative virulence of Beauveria bassiana isolates (Ascomycota : Hypocreales) associated with the greenhouse shore fly, Scatella tenuicosta (Diptera : Ephydridae). Biological Control 45: 154-162.

[3] Peng J-G, Sun Y-H, Dou B-Q, Wang P, Xin F-L, et al. (2012) Pests Controlling Effect of Azadirachtin and Azadirachta Residue and Their Influnce on Melon Grouth in Greenhouse (In Chinese). Hubei Agricultural Sciences 51: 515-517.

[4] Ugine TA, Sanderson JP, Wraight SP (2007) Developmental times and life tables for shore flies, Scatella tenuicosta (Diptera : Ephydridae), at three temperatures. Environ Entomol 36: 989-997.

[5] Luo J, Zhuang Q (2006) Biological Characteristics and Control of Sciaridae: Edible Fungi Pests (In Chinese). Chinese Journal of Tropical Crops 27: 83-86.

[6] Xu BL, Wang YX, Liu XX, Yuan F, Su N, et al. (2006) Effects of CryIAc and secondary metabolites in Bt transgenic cottonseed on Lycoriella pleuroti Yang et Zhang (Diptera : Sciaridae). Environ Entomol 35: 807-810.

[7] Vanninen I, Koskula H (2003) Biological control of the shore fly (Scatella tenuicosta) with steinernematid nematodes and Bacillus thuringiensis var. thuringiensis in peat and rockwool. Biocontrol Science and Technology 13: 47-63.

[8] Vanninen I, Koskula H (2004) Biocontrol of the shore fly Scatella tenuicosta with Hypoaspis miles and $\mathrm{H}$-aculeifer in peat pots. Biocontrol 49: 137-152.

[9] Ugine TA, Wraight SP, Sanderson JP (2013) Microbial biological control potential of three strains of Beauveria bassiana s. 1. against greenhouse shore fly Scatella tenuicosta: Assessment of virulence, mass production capacity, and effects on shore fly reproduction. Biological Control 65: 348-356. 
[10] Han JS, Park S, Shigaki T, Hirschi KD, Kim CK (2009) Improved watermelon quality using bottle gourd rootstock expressing a Ca2+/H+ antiporter. Molecular Breeding 24: 201-211.

[11] Zhao Z-G (2007) Toxic effects of mixed pesticides of fenvalerate and phoxim (NONMANYI) on spermatozoon monstrosity and micronucleus frequencies of male mice. Asian Journal of Ecotoxicology 2: 359-362.

[12] Matthiessen JN, Kirkegaard JA (2006) Biofumigation and enhanced biodegradation: Opportunity and challenge in soilborne pest and disease management. Critical Reviews in Plant Sciences 25: 235-265.

[13] Kumar ARV, Jayadevi HC, Ashoka HJ, Chandrashekara K (2003) Azadirachtin use efficiency in commercial neem formulations. Current Science 84: 1459-1464.

[14] Lynn OM, Song WG, Shim JK, Kim JE, Lee KY (2010) Effects of Azadirachtin and Neem-based Formulations for the Control of Sweetpotato Whitefly and Root-knot Nematode. Journal of the Korean Society for Applied Biological Chemistry 53: 598-604.

[15] Matthiessen JN, Shackleton MA (2000) Advantageous attributes of larval whitefringed weevil, Naupactus leucoloma (Coleoptera: Curculionidae) for bioassaying soil fumigants, and responses to pure and plant-derived isothiocyanates. Bull Entomol Res 90: 349-355.

[16] Cook SM, Smart LE, Martin JL, Murray DA, Watts NP, et al. (2006) Exploitation of host plant preferences in pest management strategies for oilseed rape (Brassica napus). Entomologia Experimentalis Et Applicata 119: 221-229.

[17] Ahuja I, Rohloff J, Bones AM (2010) Defence mechanisms of Brassicaceae: implications for plant-insect interactions and potential for integrated pest management. A review. Agronomy for Sustainable Development 30: 311-348.

[18] Troncoso-Rojas R, Corral-Acosta Y, Sanchez-Estrada A, Garcia-Estrada R, Aguilar-Valenzuela A, et al. (2009) Postharvest treatment of isothiocyanates to control Alternaria rot in netted melon. Phytoparasitica 37: 445-451.

[19] Mewis I, Ulrichs C (2001) Treatment of rice with diatomaceous earth and effects on the mortality of the Red flour beetle Tribolium castaneum (Herbst). Anzeiger fuer Schaedlingskunde 74: 13-16.

[20] Cloyd RA, Dickinson A (2005) Effects of growing media containing diatomaceous earth on the fungus gnat Bradysia sp nr. coprophila (Lintner) (Diptera : sciaridae). Hortscience 40: 1806-1809. 